\title{
Synthesis and Characterization of Cerium Molybdate Semiconductor Nanoparticles
}

\author{
Michael Segundo Sena ${ }^{a}$, Maitê Medeiros de Santana e Silva ${ }^{a}$, Andarair Gomes dos Santos ${ }^{b}$, André
}

Luis Lopes-Moriyama ${ }^{a}$, Carlson Pereira de Souza ${ }^{a}$

\author{
${ }^{a}$ Department of Graduation in Chemical Engineering, Universidade Federal do Rio Grande do Norte - \\ UFRN, 59.078-970, Natal, RN, Brazil \\ ${ }^{b}$ Department of Agrotechnology and Social Sciences, Universidade Federal Rural do Semi-Arido - \\ UFERSA, 59.600-000, Mossoró, RN, Brazil
}

Received: January 17, 2017; Revised: September 06, 2017; Accepted: September 17, 2017

\begin{abstract}
Cerium molybdate semiconductive nanoparticles were synthesized by the EDTA-citrate combined complexation method. Gel thermal degradation behavior, phase formation, morphology, composition and band gap of cerium molybdate powders were characterized by TG/DSC, XRD, SEM/EDS and DRS analysis, respectively. The nanoparticles were synthesized by fixing the $\mathrm{pH}$ of the reaction medium to 9 , producing an organometallic gel which was heated to $230^{\circ} \mathrm{C}$ obtaining a precursor powder. The precursors were calcined in a temperature range of $450-800{ }^{\circ} \mathrm{C}$ for $3 \mathrm{~h}$. The cerium molybdate powders were characterized and the phase evolution, morphology and band gap changes with the increase of calcining temperature were investigated. It was observed that the calcining temperature directly influences the formation of the crystalline structure, appearance of other phases in the materials and the particle size.
\end{abstract}

Keywords: Cerium molybdate, semiconductors, synthesis by EDTA-Citrate method, optical band gap

\section{Introduction}

Cerium molybdate $\left(\mathrm{Ce}_{2}\left(\mathrm{MoO}_{4}\right)_{3}\right)$ is an important yellow inorganic material of scheelite type with monoclinic crystalline structure that has been extensively studied by the scientific community due to its photoluminescent and photonics properties ${ }^{1}$. It has been used as corrosion inhibitor in metallic alloys ${ }^{2}$, photocatalyst in the decomposition of dyes $^{3}$, photocatalyst with antibacterial action ${ }^{4}$ and many other applications.

Nanostructured semiconductors have been commonly used in optoelectronics and photovoltaic devices, and the interest in investigating the photoelectrochemical properties of these materials have been increased every day ${ }^{5}$. The photocatalytic process is based in a reaction where a semiconductor is activated with light emission with sufficient energy to excite the electrons from the valence band to the conduction band forming an electron-hole pair, the region between the bands is called bandgap.

Many nanomaterials have been explored for applications as photocatalysts with high efficiency. For example, titanium dioxide $\left(\mathrm{TiO}_{2}\right.$ ) nanostructures have been systematically studied and have demonstrated high potential as photocatalysts under UV irradiation ${ }^{6,7}$. However, the limitation of having to work with a wavelength restricted to UV has given rise to new researches in the area, in order to develop materials with promising photocatalytic action within the visible spectrum of light.

*e-mail: michael2.senna@gmail.com.
Studies have shown that rare earth molybdates with $\mathrm{R}_{2}\left(\mathrm{MoO}_{4}\right)_{3}$ structure, with $\mathrm{R}=\mathrm{La}, \mathrm{Ce}, \mathrm{Pr}, \mathrm{Nd}, \mathrm{Sm}$ e Eu are essentially electronic semiconductors ${ }^{8}$. Besides, rare earth molybdates with optoelectronic and photocatalytic properties have been reported in many publications ${ }^{5,9,10,11}$, standing out the cerium molybdate.

The synthesis of cerium molybdate nanostructures has been reported in the literature by several different methods which in turn affect its crystalline structure, such as co-precipitation ${ }^{12}$ (amorphous material), hydrothermal ${ }^{13}$ $\left(\mathrm{Ce}_{2}\left(\mathrm{MoO}_{4}\right)_{3} \cdot 4.5 \mathrm{H}_{2} \mathrm{O}\right.$ with unknown crystalline structure $)$, microwave-hydrothermal/solvothermal ${ }^{1}\left(\mathrm{Ce}_{2}\left(\mathrm{MoO}_{4}\right)_{3}\right.$ with unknown crystalline structure), and sol-gel ${ }^{2}\left(\mathrm{Ce}\left(\mathrm{MoO}_{4}\right)_{2}\right.$ with tetragonal structure).

Due to the instability of the cerium ion at high temperatures, which can change its oxidation state $\left(\mathrm{Ce}^{3+} / \mathrm{Ce}^{4+}\right)$, there is a certain difficulty in synthesizing a well-crystallized singlephase cerium molybdate with its appropriate crystalline structure, monoclinic symmetry ${ }^{14}$. Hence, the synthesis method has an important role in the structure of the material, and consequently in its electronic properties.

The EDTA-citrate complexing method, a modified Pichine type reaction, is a polymerized complex method to synthesize a wide variety of oxide materials ${ }^{15}$. Ceramic powders are usually synthesized by the conventional solidstate reaction (SSR) method. Compared to SSR method, wet chemical methods, such as EDTA-citrate, is preferable when employing various ceramic materials. The ceramic 
powders prepared by EDTA-citrate complexing method are calcined at relative low temperature and only requires a short period of time because the reagents are mixed on the molecular scale. The powder produced exhibits small particle size, high specific surface area, uniform element and particle size distribution, which contributes for catalytic and photocatalytic applications ${ }^{16},{ }^{17}$.

In the present paper, we report for the first time the synthesis of pure crystalline cerium molybdate powders using the EDTA-citrate complexing method at four different calcining temperatures, and we show the phase evolution of the powders, the modifications in the structure, morphology and in the band gap of the material.

\section{Materials and Methods}

\subsection{Synthesis of organometallic precursors}

The precursor powders were obtained by EDTA-citrate complexing method. The experimental procedure was given as follows: First of all, EDTA $\left(\mathrm{C}_{10} \mathrm{H}_{16} \mathrm{~N}_{2} \mathrm{O}_{8}\right)$ was diluted to ammonium hydroxide $\left(\mathrm{NH}_{4} \mathrm{OH}\right)$ in ratio of $1 \mathrm{~g}: 10 \mathrm{~mL}$ under stirring and controlled temperature $\left(40^{\circ} \mathrm{C}\right)$. Then, the sources of $\mathrm{Ce}$ and Mo cations $\left(\mathrm{Ce}\left(\mathrm{NO}_{3}\right)_{3} \cdot 6 \mathrm{H}_{2} \mathrm{O}\right.$ and $\left.\left(\mathrm{NH}_{4}\right)_{6} \mathrm{Mo}_{7} \mathrm{O}_{24} \cdot 4 \mathrm{H}_{2} \mathrm{O}\right)$ were added, maintaining constant temperature and stirring. Then, citric acid $\left(\mathrm{C}_{2} \mathrm{H}_{4} \mathrm{O}_{2}\right)$ was added and the temperature was increased $\left(80^{\circ} \mathrm{C}\right)$. The solution $\mathrm{pH}$ was adjusted to 9 with addition of ammonium hydroxide, and the solution was maintained under such conditions until formation of the organometallic gel. Then, the gel was pre-calcined to form the precursor powder.

\subsection{Samples preparation}

Four samples were prepared by calcining the precursors in a muffle furnace at $450,500,600$ and $800^{\circ} \mathrm{C}$ at a rate of $5^{\circ} \mathrm{C} \cdot \mathrm{min}^{-1}$ for $3 \mathrm{~h}$ for further analysis.

\subsection{Characterizations}

\subsubsection{Thermogravimetric / differential scanning calorimetry (TG / DSC)}

The decomposition behavior of the precursor gel was analyzed by thermogravimetry-differential analysis (TG/DSC, STA 449F3, Netznetzsch) at a heating rate of $5^{\circ} \mathrm{C} \cdot \mathrm{min}^{-1}$ up to $1200^{\circ} \mathrm{C}$ for a sample mass of $13.49 \mathrm{mg}$ in alumina crucible.

\subsubsection{X-Ray diffraction $(X R D)$}

The phase identification of the synthesized powders, which were calcined at various temperatures, was performed by X-ray diffraction (XRD, D2 Phaser, Bruker) with $\mathrm{Cu}-\mathrm{K} \alpha$ $(\lambda=1.5406 \AA)$ radiation at a scan rate of $0.01^{\circ} . \mathrm{s}^{-1}$ in the $2 \theta$ range from $10^{\circ}$ to $80^{\circ}$.

\subsubsection{Rietveld refinement}

The structural parameters of the powders were obtained by Rietveld refinement analysis of the powder diffraction data using Material Analysis Using Diffraction (MAUD) software version 2.064 .

\subsubsection{Field emission scanning electron microscopy/ energy dispersive spectroscopy (SEM/EDS)}

The morphology of the synthesized powders was determined using a Field Emission Scanning Electron Microscope (FEG SEM, Auriga, Carl Zeiss, USA) operated with an incident electron beam of $30 \mathrm{kV}$ coupled to a microanalysis system of Energy Dispersive Spectroscopy (EDS, SwiftED3000, Oxford Instruments, USA) for quantification and chemical composition analysis. Prior to analysis, the samples were pre-treated, they were suspended in ethanol and dried at 100 ${ }^{\circ} \mathrm{C}$ for dispertion. Then, the samples were metallized with gold for $30 \mathrm{~s}$ and $30 \mathrm{~mA}$ in a metallizer (Sputter Coater, SCD 005, Baltec, USA).

\subsubsection{Diffuse reflectance spectroscopy (DRS)}

The band gap of the powders was analyzed by diffuse reflectance spectroscopy using an UV-Vis spectrophotometer (DRS, 5G, NIR Cary) in the wavelength range $200-800$ $\mathrm{nm}$, all measurements were performed at room temperature using barium sulfate $\left(\mathrm{BaSO}_{4}\right)$ as the reference sample for reflectance measurements.

\section{Results and Discussion}

\subsection{Thermogravimetry-differential analysis}

Figure 1 illustrates the thermal decomposition behavior of the dried cerium molybdate gel.

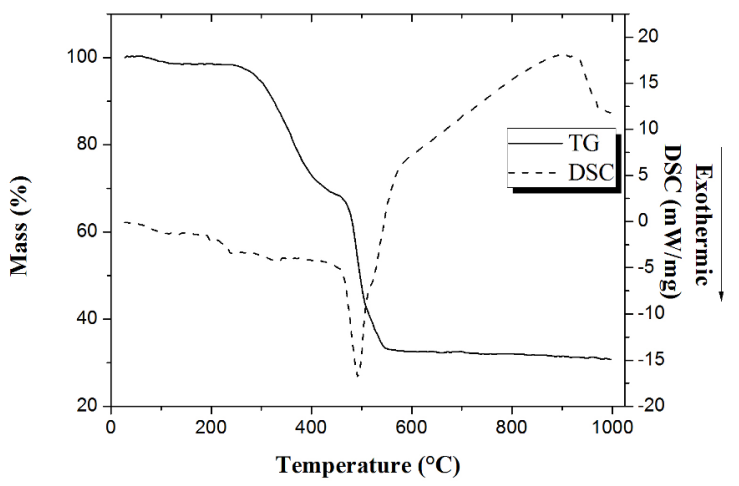

Figure 1. Thermogravimetric analysis curve for cerium molybdate precursors.

The TG of the precursor has three mass-loss steps. In the first step the decomposition occurs between $60^{\circ} \mathrm{C}$ and $130^{\circ} \mathrm{C}$ associated with a weight loss of $2.5 \%$ due to the elimination of residual water and ammonia from the ge ${ }^{18}$. There is also another abrupt weight loss (30\%) in the temperature range $250-460{ }^{\circ} \mathrm{C}$, attributed to the decomposition of the chelates and formation of the organometallic complexes. The third step in the temperature range $460-560{ }^{\circ} \mathrm{C}$ is related to a weight loss of $35.58 \%$ and it's followed by a strong and sharp 
exothermic peak at $500^{\circ} \mathrm{C}$ on the DSC curve, corresponding to the pyrolysis of the organometallic complex which gives rise to intermediate oxides until formation of crystalline cerium molybdate. Thereafter, there is no further weight loss above $560^{\circ} \mathrm{C}$, but an endothermic event continues between $560{ }^{\circ} \mathrm{C}$ and $1000{ }^{\circ} \mathrm{C}$, which indicates that changes in the crystalline structure may occur in this interval.

\subsection{Powder X-ray diffraction}

As was described by Brazdil (2015) $)^{14}$, the ideal scheelite structure has a tetragonal unit cell with space group $I 4_{1} / \mathrm{a}$ (with general formula $\mathrm{ABO}_{4}$, based on $\mathrm{CaWO}_{4}$ ) where $\mathrm{A}^{2+}$ is a large cation which is 8-coordinated by oxygen, and $\mathrm{B}^{6+}$ is a small cation which is tetrahedrally coordinated by oxygen. The incorporation of a trivalent cation in the divalent cation site of the normal scheelite produces a defect structure containing cation vacancies needed for electro-neutrality, crystallizing in a superstructure with monoclinic symmetry, and the resulting empirical formula is $\mathrm{A}_{2} \mathrm{r}\left(\mathrm{BO}_{4}\right)_{3}$, where $\mathrm{r}$ indicates a cation vacancy ${ }^{14}$. Furthermore, it stands out that when A cation is cerium there exists optionality for multiple oxidation state $\left(\mathrm{Ce}^{3+} / \mathrm{Ce}^{4+}\right)$.

Figure 2 shows the $\mathrm{X}$-ray diffraction patterns for the cerium molybdate powders calcined in a temperature range of $450-800{ }^{\circ} \mathrm{C}$.

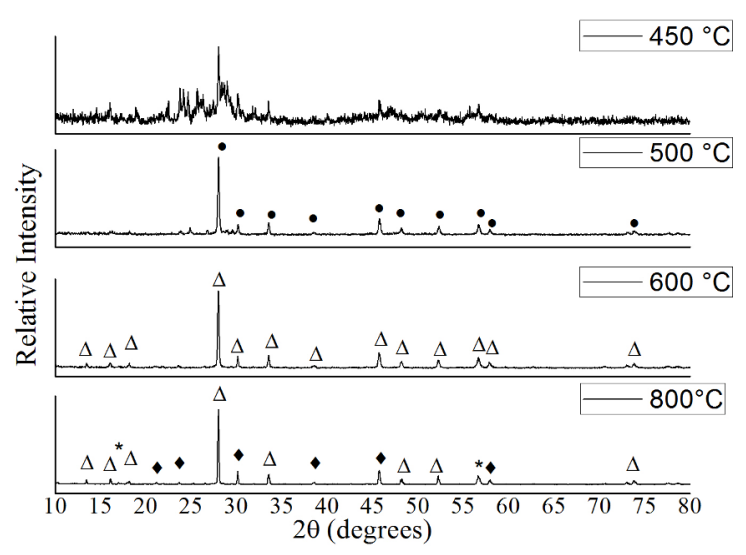

Figure 2. X-ray diffraction patterns of cerium molybdate powders. Symbols legend: •- tetragonal $\mathrm{Ce}_{2}\left(\mathrm{MoO}_{4}\right)_{3}, \Delta$ - monoclinic $\mathrm{Ce}_{2}\left(\mathrm{MoO}_{4}\right)_{3}$, - $\mathrm{Ce}_{11} \mathrm{O}_{20}, *-\mathrm{Ce}_{7} \mathrm{O}_{12}$.

The diffractogram of the powders calcined at $450{ }^{\circ} \mathrm{C}$ shows some of the characteristic peaks of cerium molybdate but with many noises and broad peaks, indicating that the material is not completely crystalline. The pattern of the powder calcined at $500{ }^{\circ} \mathrm{C}$ could be indexed to tetragonal $\mathrm{La}_{2}\left(\mathrm{MoO}_{4}\right)_{3}$ (JCPDS card No. 045-04-07). The pattern of the material calcined at $600{ }^{\circ} \mathrm{C}$ could be indexed to monoclinic $\mathrm{La}_{2}\left(\mathrm{MoO}_{4}\right)_{3}$ (JCPDS card No. 01-070-1382), indicating crystalline structure changes of the material as the calcining temperature is increased. This is observed in the sample calcined at $600{ }^{\circ} \mathrm{C}$ from the distinct presence of intense primitive scheelite (tetragonal) diffraction peaks $\left(28^{\circ}-34^{\circ}\right.$ and $\left.46^{\circ}-58^{\circ}\right)$, plus the weaker low-angle (10 $\left.{ }^{\circ}-25^{\circ}\right)$ superstructure diffraction peaks which are the fingerprints of the defect monoclinic phase ${ }^{19}$. The pattern of the powders calcined at $800{ }^{\circ} \mathrm{C}$ shows the diffraction peaks of the monoclinic phase, but it was also observed the appearance of $\mathrm{Ce}_{11} \mathrm{O}_{20}$ and $\mathrm{Ce}_{7} \mathrm{O}_{12}$ phases due to cerium oxidation. This result was also related by Brazdil et al. $(2015)^{19}$ that demonstrated the appearance of $\mathrm{CeO}_{2}$ phases in the synthesis of cerium molybdate at temperatures above $600^{\circ} \mathrm{C}$. The diffractograms of the cerium molybdate powders were indexed with lanthanum molybdate cards, as they are isostructural and due to the unavailability of tetragonal and monoclinic cerium molybdate cards in the literature.

\subsection{Rietveld refinement}

The structural parameters were obtained from Rietveld refinement method using powder XRD data using MAUD software version 2.064 . The patterns were typically refined for lattice parameters, unit cell volume and mean crystallite size. The experimental, computed and deviation XRD patterns of $\mathrm{Ce}_{2}\left(\mathrm{MoO}_{4}\right)_{3}$ are shown in Figure 3 .

The refinement results show the tetragonal cerium molybdate with space group $\mathrm{I}_{1} / \mathrm{a}$ and the monoclinic cerium molybdate with space group $\mathrm{C} 2 / \mathrm{c}$. The refined structural parameters are summarized in Table 1.

The lattice parameters (a, b, c) shown in Tab. 1 are used to describe the unit cell of the crystalline structure. The results confirm that the material calcined at $500^{\circ} \mathrm{C}$ has a tetragonal structure and the materials calcined at $600{ }^{\circ} \mathrm{C}$ and $800^{\circ} \mathrm{C}$ have monoclinic structure. The lattice parameters obtained in the refinement are very close to the ones of the monoclinic cerium molybdate obtained by Maisang et al. $(2016)^{1}(a=16.8762 \AA, b=11.8402 \AA, c=15.9742 \AA, \beta$ $=108.679^{\circ}$ and cell volume $=3023.79 \AA^{3}$ ). The results also revealed that the average crystallite size of the particles grew up with increasing temperature, going from $1467.43 \AA$ to $18526.18 \AA$. The reliability of the data exposed on Tab. 1 is a function of the residual parameter (S), being greater when close to the unity.

\subsection{Morphological characterization}

Figure 4 shows the SEM images of the cerium molybdate powders synthesized at calcining temperature range of 450 $-800{ }^{\circ} \mathrm{C}$ and heating rate of $5^{\circ} \mathrm{C} \cdot \mathrm{min}^{-1}$.

Fig. 4 (a - d) shows a set of agglomerates of irregularly shaped particles. It is observed that the increase in temperature does not affect the shape of the particles. At $450{ }^{\circ} \mathrm{C}$, the particles are larger than in the other temperatures, with average size of $328.57 \mathrm{~nm}$. It is due to the fact that there are still carbonates and other organic residues, such as the organometallic complexes formed during the reaction, present in the material composition. These organic residues are completely degraded at about $500{ }^{\circ} \mathrm{C}$ as also confirmed by the TGA measurements in Fig.1, producing carbon monoxide and carbon dioxide, leaving only the oxide of interest in the 

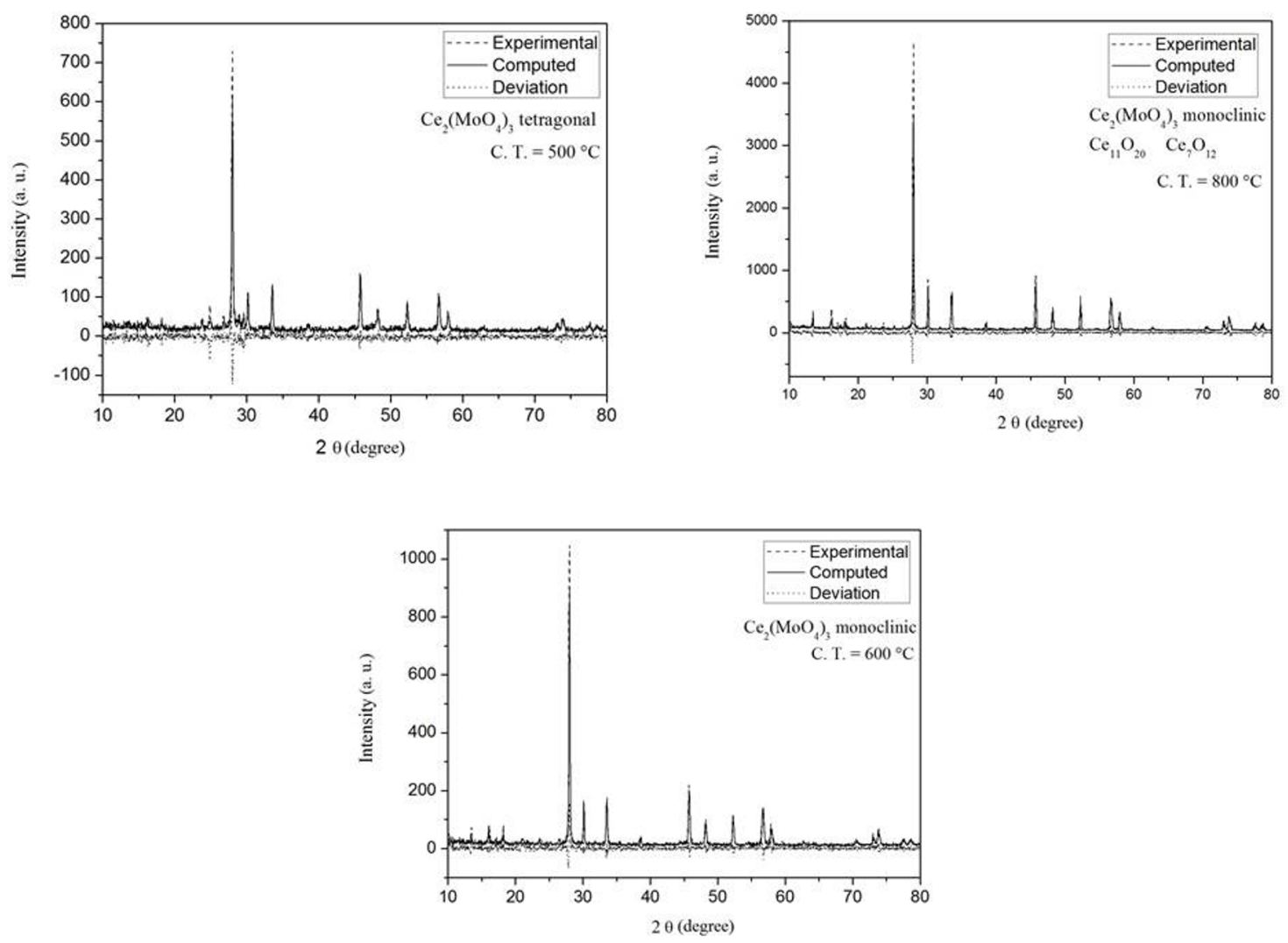

Figure 3. Observed, computed and deviation XRD patterns of $\mathrm{Ce}_{2}\left(\mathrm{MoO}_{4}\right)_{3}$.

Table 1. Lattice parameters, cell volume and average crystallite size from Rietveld refinement of X-ray diffraction data of the samples calcined at 500,600 and $800^{\circ} \mathrm{C}$.

\begin{tabular}{lccc}
\hline Compounds - Calcining temperature & $\mathrm{Ce}_{2}\left(\mathrm{MoO}_{4}\right)_{3}-500{ }^{\circ} \mathrm{C}$ & $\mathrm{Ce}_{2}\left(\mathrm{MoO}_{4}\right)_{3}-600{ }^{\circ} \mathrm{C}$ & $\mathrm{Ce}_{2}\left(\mathrm{MoO}_{4}\right)_{3}+$ cerium oxides $-800{ }^{\circ} \mathrm{C}$ \\
\hline Crystalline structure & tetragonal & monoclinic & monoclinic \\
Space group & $\mathrm{I} 41 / \mathrm{a}$ & $\mathrm{C} 2 / \mathrm{c}$ & $\mathrm{C} 2 / \mathrm{c}$ \\
Lattice parameters & & & 16.877 \\
$\mathrm{a}(\AA)$ & 16.859 & 16.901 & 11.840 \\
$\mathrm{~b}(\AA)$ & 16.859 & 11.839 & 15.976 \\
$\mathrm{c}(\AA)$ & 16.013 & 15.980 & 90 \\
$\alpha=\gamma\left({ }^{\circ}\right)$ & 90 & 90 & 108.251 \\
$\beta\left({ }^{\circ}\right)$ & 90 & 108.487 & 3164.03 \\
Cell volume $\left(\AA^{3}\right)$ & 4550.99 & 3181.01 & 18526.18 \\
Average crystallite size $(\AA)$ & 1467.43 & 2495.15 & 1.98 \\
Residual parameter, $\mathrm{S}$ & 1.29 & 1.28 & \\
\hline
\end{tabular}

powder ${ }^{18}$, resulting in a material with smaller particle size. The XRD diffractograms previously discussed in Fig. 2 also confirm that the material calcined at $450^{\circ} \mathrm{C}$ is not completely crystalline, which is attributed to the presence of organic residues in the composition ${ }^{18}$. At 600 and $800^{\circ} \mathrm{C}$, it is possible to notice the joining of two or more particles forming larger particles; it is more remarkable at $800^{\circ} \mathrm{C}$. This phenomenon, within the related temperature, is explained by the decrease in Gibbs free energy caused by the decrease of the surface area. It is not observed a considerable increase in size of the particles in the temperatures of 500,600 and $800{ }^{\circ} \mathrm{C}$, with average size of $159.51,169.75$ and $189.01 \mathrm{~nm}$, respectively.

\subsection{Composition analysis}

Table 2 shows the EDS results of cerium molybdate samples calcined in the temperature range of $450-800{ }^{\circ} \mathrm{C}$. 


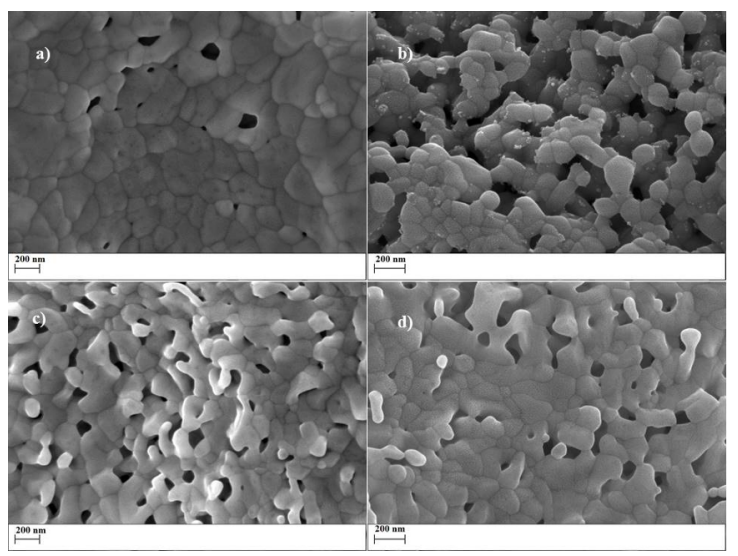

Figure 4. SEM images of cerium molybdate powders $\left(\mathrm{a}=450^{\circ} \mathrm{C}\right.$; $\left.\mathrm{b}=500^{\circ} \mathrm{C} ; \mathrm{c}=600^{\circ} \mathrm{C} ; \mathrm{d}=800^{\circ} \mathrm{C}\right)$.

The theoretical atomic composition of $\mathrm{Ce}_{2}\left(\mathrm{MoO}_{4}\right)_{3}$ is $40 \%$ and $60 \%$ of Ce and Mo, respectively, not considering the oxygen in the composition. The presence of $\mathrm{Ce}$ and $\mathrm{Mo}$ in the samples was confirmed by the EDS analysis. The sample calcined at $600^{\circ} \mathrm{C}$ has the best approximation with the theoretical values, this agrees with the TG and XRD analysis, because the samples calcined at temperatures below $600^{\circ} \mathrm{C}$ did not yield the monoclinic cerium molybdate, and at $800^{\circ} \mathrm{C}$ cerium oxides were yielded which increased the percentage of cerium in relation to molybdenum.

\subsection{Optical band gap analysis}

The optical energy band gap $\left(E_{g a p}\right)$ of the as-synthesized $\mathrm{Ce}_{2}\left(\mathrm{MoO}_{4}\right)_{3}$ were estimated from UV-Vis absorption spectra using the equation proposed by Wood-Tauc ${ }^{20}$. According to these researchers, the energy gap $\left(E_{g a p}\right)$ is related to the absorbance and the photon energy by the Eq (1):

$$
\alpha h v=A\left(h v-E_{g a p}\right)^{n}
$$

Where $\alpha$ is the absorbance, $A$ is a proportionality constant, $h$ is the Planck constant, $v$ is the frequency and $E_{g a p}$ is the optical band gap, $n$ is a variable that depends on the kind of electronic transition $(n=1 / 2,2,3 / 2$ or 3 for allowed direct, allowed indirect, forbidden direct or forbidden indirect, respectively). Cerium molybdate has been related with direct electronic transition ${ }^{1}$, so we considered the value $n=1 / 2$ in Eq (1) for calculating the optical band gap.

Figure 5 show the plots of $(\alpha h v)^{2}$ versus the photon energy $(h v)$ of the as-synthesized $\mathrm{Ce}_{2}\left(\mathrm{MoO}_{4}\right)_{3}$ calcined at 500,600 and $800{ }^{\circ} \mathrm{C}$.

Therefore, the optical band gap was determined by the extrapolation of the linear portion of the curve to zero absorbance. When the photon energy is greater than the energy gap, the absorption linearly increases with the increase of the photon energy. The steep inclination of the linear portion of the curve is caused by the absorption for charge diffusion from the valence band to the conduction band.
Table 2. Atomic percentages of Ce and Mo by EDS analysis of cerium molybdate samples calcined in the temperature range $450^{\circ} \mathrm{C}-800^{\circ} \mathrm{C}$.

\begin{tabular}{lllll}
\hline Element & $450{ }^{\circ} \mathrm{C}$ & $500{ }^{\circ} \mathrm{C}$ & $600{ }^{\circ} \mathrm{C}$ & $800{ }^{\circ} \mathrm{C}$ \\
\hline Ce (\%) & 49.693 & 45.818 & 39.231 & 46.95 \\
Mo (\%) & 50.307 & 54.182 & 60.769 & 53.05 \\
\hline
\end{tabular}

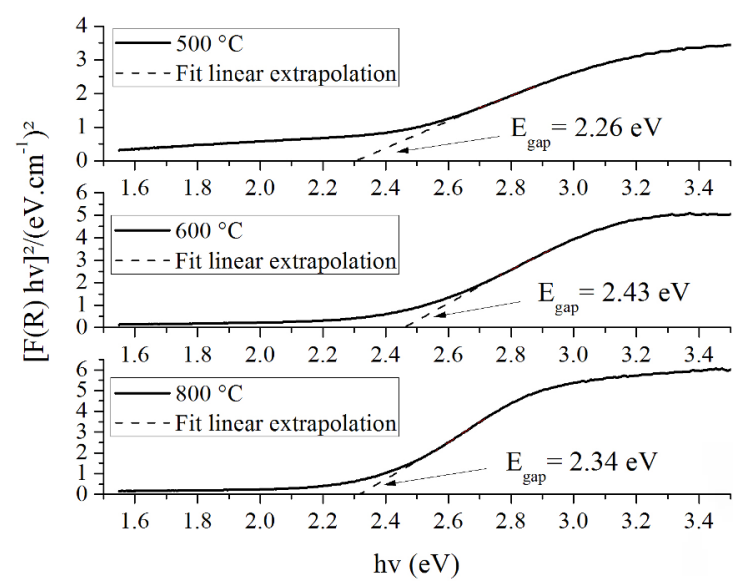

Figure 5. UV-vis absorbance spectra at room temperature for the $\mathrm{Ce}_{2}\left(\mathrm{MoO}_{4}\right)_{3}$ powders processed EDTA-citrate at 500, 600 and $800^{\circ} \mathrm{C}$ for $3 \mathrm{~h}$.

The energy difference between the valence and conduction bands is denominated as the band gap characterized by a certain crystal momentum vector in the Brillouin zone. For photon energy smaller than the energy gap, the absorbance curve becomes different from linearity, due to the absorption of charge diffusion relating to different defects ${ }^{1}$. There are several parameters that affect the energy gap such as the electronegativity of transition metal ions, connectivity of the polyhedrons, defects, degree of crystallinity, structure, crystallite size, impurities, product morphologies and others ${ }^{21}$.

UV-vis measurements on the three samples showed typical values of $E_{\text {gap }}=2.26 \mathrm{eV}, 2.43 \mathrm{eV}$ and $2.34 \mathrm{eV}$ for the cerium molybdate samples calcined at 500, 600 and $800{ }^{\circ} \mathrm{C}$ respectively. At $450{ }^{\circ} \mathrm{C}$, the products are unable to be identified phases which are not able to be compared with the energy gap of the other samples. At $500{ }^{\circ} \mathrm{C}$ the direct energy gap belongs to the tetragonal phase of $\mathrm{Ce}_{2}\left(\mathrm{MoO}_{4}\right)_{3}$ which is smaller than the direct energy gap of the monoclinic phase of $\mathrm{Ce}_{2}\left(\mathrm{MoO}_{4}\right)_{3}$ synthesized at $600^{\circ} \mathrm{C}$. And the sample calcined at $800^{\circ} \mathrm{C}$, the direct energy gap belong to the mixed phases of $\mathrm{Ce}_{2}\left(\mathrm{MoO}_{4}\right)_{3}, \mathrm{Ce}_{11} \mathrm{O}_{20}$ and $\mathrm{Ce}_{7} \mathrm{O}_{12}$. The changes in the crystal structure are the reason for the differences in the energy gap values of the samples. These $E_{g a p}$ values classify the nanoparticles as semiconductor materials and are very close to $E_{g a p}=2.55 \mathrm{eV}$ calculated for cerium molybdate synthesized by solvothermal method ${ }^{3}$ and values between $E_{\text {gap }}=2.30$ and $2.80 \mathrm{eV}$ for cerium molybdate synthesized by microwave-hydrothermal/solvothermal method ${ }^{1}$. 


\section{Conclusions}

Cerium molybdate nanoparticles have been successfully synthesized by EDTA-citrate complexing method. The data revealed the structure change and appearance of cerium oxides phases with increasing temperature, the results show the optimal calcining temperature to obtain a well-crystallized single-phase material by this method at about $600^{\circ} \mathrm{C}$, which was confirmed through thermal, structural and elemental analysis. XRD patterns revealed that the material calcined at $450{ }^{\circ} \mathrm{C}$ is not completely crystalline and exhibit single tetragonal structure at $500{ }^{\circ} \mathrm{C}$, single monoclinic structure at $600^{\circ} \mathrm{C}$, and with subsequent increase of temperature to 800 ${ }^{\circ} \mathrm{C}$, cerium oxides phases appear in the monoclinic structure. Rietveld refinement revealed the structural parameters of the samples, space group, lattice parameters and main crystallite size. SEM images of the materials calcined at the temperature range of $450-800{ }^{\circ} \mathrm{C}$ showed a set of agglomerates of irregularly shaped particles. The increase in heat treatment temperature does not affect the shape of the particles, but affects its size. The composition analysis revealed that the material calcined at $600^{\circ} \mathrm{C}$ has the closest atomic composition of the theoretical atomic composition of pure cerium molybdate $\left(\mathrm{Ce}_{2}\left(\mathrm{MoO}_{4}\right)_{3}\right)$. Ultraviolet-visible absorption spectroscopy revealed a characteristic optical band gap of $2.26 \mathrm{eV}, 2.43 \mathrm{eV}$ and $2.34 \mathrm{eV}$ for the materials calcined at $500{ }^{\circ} \mathrm{C}, 600{ }^{\circ} \mathrm{C}$ and $800^{\circ} \mathrm{C}$, respectively, which is associated with the difference of energy between the valence band and conduction band, classifying the nanoparticles as semiconductors. The photocatalytic potential of cerium molybdate synthesized by EDTA-citrate method will be evaluated by the degradation of organic dyes under UV light irradiation for further publications.

\section{Acknowledgments}

Authors thank to the Graduate Program in Chemical Engineering of the Universidade Federal do Rio Grande do Norte (PPGEQ-UFRN); to Laboratory of Nanostructured Materials and Catalytic Reactors (LAMNRC-UFRN); to Molecular Sieves Laboratory (LABPMOL-UFRN); to Graduate Program in Materials Science and Engineering labs (PPGCEM-UFRN); To the Coordination of Improvement of Higher Level Personnel (CAPES), by financial support.

\section{References}

1. Maisang W, Phuruangrat A, Thongtem S, Thongtem T. Photoluminescence and photonic absorbance of $\mathrm{Ce}_{2}\left(\mathrm{MoO}_{4}\right)_{3}$ nanocrystal synthesized by microwave-hydrothermal/ solvothermal method. Rare Metals. 2016 DOI: 10.1007/s12598-016-0714-7

2. Kartsonakis IA, Kordas G. Synthesis and Characterization of Cerium Molybdate Nanocontainers and Their Inhibitor Complexes. Journal of the American Ceramic Society. 2010;93(1):65-73.
3. Ayni S, Sabet M, Salavati-Niasari M, Hamadanian M. Synthesis and characterization of cerium molybdate nanostructures via a simple solvothermal method and investigation of their photocatalytic activity. Journal of Materials Science: Materials in Electronics. 2016;27(7):7342-7352.

4. Kartsonakis IA, Kontogiani P, Pappas GS, Kordas G. Photocatalytic action of cerium molybdate and iron-titanium oxide hollow nanospheres on Escherichia coli. Journal of Nanoparticle Research. 2013;15(6):1759.

5. Kwolek P, Pilarczyk K, Tokarski T, Łapczyńska M, Pacia M, Szaciłowski K. Lead molybdate - a promising material for optoelectronics and photocatalysis. Journal of Materials Chemistry C. 2015;3(11):2614-2623.

6. Kaur K, Pal B. Selective formation of benzo[c]cinnoline by photocatalytic reduction of 2,2'-dinitrobiphenyl using $\mathrm{TiO}_{2}$ and under UV light irradiation. Chemical Communications. 2015;51(40):8500-8503.

7. Li JR, Yang CH, Wu LG, Cao YQ, Wang T, Jiang BQ. Enhancement on the performance of $\mathrm{TiO}_{2}$ photocatalysts under weak UV light irradiation via asorbed-layer nanoreactor technique. Colloids and Surfaces A: Physicochemical and Engineering Aspects. 2015;481:413-422.

8. Gaur K, Singh M, Lal HB. Electrical transport in light rare-earth molybdates. Journal of Materials Science. 1993;28(14):38163822 .

9. Dutta S, Som S, Priya J, Sharma SK. Band gap, CIE and trap depth parameters of rare earth molybdate phosphors for optoelectronic applications. Solid State Sciences. 2013;18:114122.

10. Edrissi M, Samadanian-Isfahani S, Soleymani M. Preparation of cobalt molybdate nanoparticles; Taguchi optimization and photocatalytic oxidation of Reactive Black 8 dye. Powder Technology. 2013;249:378-385.

11. Yousefi T, Khanchi AR, Ahmadi SJ, Rofouei MK, Yavari R, Davarkhah R, et al. Cerium(III) molybdate nanoparticles: Synthesis, characterization and radionuclides adsorption studies. Journal of Hazardous Materials. 2012;215-216:266-271.

12. Yasakau KA, Tedim J, Zheludkevich ML, Drumm R, Shem M, Wittmar M, et al. Cerium molybdate nanowires for active corrosion protection of aluminium alloys. Corrosion Science. 2012;58:41-51.

13. Dong M, Lin Q, Sun H, Chen D, Zhang T, Wu Q, et al. Synthesis of Cerium Molybdate Hierarchical Architectures and Their Novel Photocatalytic and Adsorption Performances. Crystal Growth \& Design. 2011;11(11):5002-5009.

14. Brazdil JF. Scheelite: a versatile structural template for selective alkene oxidation catalysts. Catalysis Science \& Technology. 2015;5(7):3452-3458

15. Ding X, Liu Y, Gao L, Guo L. Synthesis and characterization of doped $\mathrm{LaCrO}_{3}$ perovskite prepared by EDTA-citrate complexing method. Journal of Alloys and Compounds. 2008;458(1-2):346350 .

16. Cao Y, Zhu K, Zheng H, Qiu J, Gu H. Synthesis of potassium sodium niobate powders using an EDTA/citrate complexing sol-gel method. Particuology. 2012;10(6):777-782. 
17. Hung IM, Chiang YJ, Lee SW, Chang JK, Lin JC, Jang JSC, et al. Material characterization and electrochemical performance of $\mathrm{Sr}\left(\mathrm{Ce}_{0.6} \mathrm{Zr}_{0.4}\right)_{0.8} \mathrm{Y}_{0.2} \mathrm{O}_{3-\delta}$ proton conducting ceramics prepared by EDTA-citrate complexing and solid-state reaction methods. Journal of the Ceramic Society of Japan. 2015;123(1436):187-192.

18. Patra H, Rout SK, Pratihar SK, Bhattacharya S. Effect of process parameters on combined EDTA-citrate synthesis of $\mathrm{Ba}_{0.5} \mathrm{Sr}_{0.5} \mathrm{Co}_{0.8} \mathrm{Fe}_{0.2} \mathrm{O}_{3-\delta}$ perovskite. Powder Technology. 2011;209(1-3):98-104.
19. Brazdil JF, Toft MA, Lin SSY, McKenna ST, Zajac G, Kaduk JA, et al. Characterization of bismuth-cerium-molybdate selective propylene ammoxidation catalysts. Applied Catalysis A: General. 2015;495:115-123.

20. Wood DL, Tauc J. Weak Absorption Tails in Amorphous Semiconductors. Physical Review B. 1972;5(8):3144-3151.

21. Keereeta Y, Thongtem T, Thongtem S. Synthesis of lanthanum tungstate interconnecting nanoparticles by high voltage electrospinning. Applied Surface Science. 2015;351:1075-1080. 